\title{
Surface Oxides of Activated Carbon: Internal Reflectance Spectroscopic Examination of Activated Sugar Carbons
}

\author{
JAMES S. MATTSON, ${ }^{1}$ LYON LEE, ${ }^{2}$ HARRY B. MARK, JR., ${ }^{2}$ \\ AND WALTER J. WEBER, JR. ${ }^{3}$ \\ University of Michigan, Ann Arbor, Michigan 48104
}

Received October 24, 1969; accepted December 15, 1969

\begin{abstract}
The nature of the activated carbon surface with respect to surface functional groups has been examined using infrared internal reflectance spectroscopy (IRS). By employing this recently developed technique, the surface character of laboratory-activated sugar carbons has been examined as a function of activation temperature and atmosphere. The IRS spectra obtained for series of $\mathrm{O}_{2}$ and $\mathrm{CO}_{2}+\mathrm{O}_{2}$ activated carbons indicate the presence of dicarboxylic acids and quinone carbonyl groups. The adsorption isotherms of $p$-nitrophenol on these carbons has been studied and has been shown to conform with the previously suggested adsorption mechanism involving the formation of a donor-acceptor complex with surface carbonyl oxygen.
\end{abstract}

\section{INTRODUCTION}

The surface chemistry of active carbon has been a subject of intensive interest for more than a century (1-3); yet surprisingly little is known about the precise nature of the surface functional groups of this material. The present study is part of a detailed examination of the character of functional groups formed on active carbon under different conditions of activation, using the recently developed technique of internal reflectance spectroseopy as a means for characterizing surface functional groups. Temperature of activation and activating atmosphere are the particular variables studied in the experimental work reported in this paper.

Commercial carbons are generally activated in an atmosphere of $\mathrm{CO}_{2}, \mathrm{CO}, \mathrm{O}_{2}$, $\mathrm{H}_{2} \mathrm{O}$ vapor, and occasionally other selected

1 Water Resources Science, University of Michigan, Ann Arbor, Michigan 48104.

Present address: Chemistry Department, Gulf General Atomic, Inc., P.O. Box 608, San Diego, Cal. 92112.

2 Department of Chemistry, University of Michigan, Ann Arbor, Michigan 48104.

${ }^{3}$ Department of Civil Engineering, University of Michigan, Ann Arbor, Michigan 48104. gases, at a temperature between $300^{\circ}$ and $800^{\circ} \mathrm{C}$, often followed by quenching in air or water. Because of the "impure" nature of the raw materials used in the production of commercial carbons and because of the concentration and temperature gradients that develop within the beds of carbon during activation, very heterogeneous or, at best, difficult to characterize surfaces usually result. It has been shown previously that these heterogeneous surfaces produce a poor-contrast, difficult-to-interpret infrared IRS spectrum. Thus, for the present work, infrared IRS studies were carried out on several series of activated sugar chars, prepared under very uniform and reproducible conditions in the laboratory.

Oxygen has been shown previously to react to a significant extent with activated carbons (2-5). In fact, it has been shown $(2-5)$ that carbons activated in an atmosphere of pure $\mathrm{CO}_{2}$, or in a vacuum, react with molecular oxygen at room temperature and below. Zarif'yanz et al. (4) actually were able to demonstrate that oxygen is irreversibly "chemisorbed" on graphite wear dust at temperatures below $-40^{\circ} \mathrm{C}$. This irreversibly adsorbed oxygen is re- 
movable only as $\mathrm{CO}_{2}$ and $\mathrm{CO}$ at temperatures above $200^{\circ} \mathrm{C}$ (4). This affinity for irreversibly "chemisorbed" oxygen strongly suggests the formation of organic oxygen functional groups on the carbon surface.

Several types of oxygen surface groups have been postulated to explain these phenomena, and two excellent recent reviews $(6,7)$ are available in the literature. From the previous studies on the subject, it is the consensus that two general types of oxygen functional groups are present on an active carbon surface: those which desorb as $\mathrm{CO}$, and those which desorb as $\mathrm{CO}_{2}$. Shelef and Walker (8) have proposed a model for hightemperature oxidation of carbon which involves only two types of surface groups, one of very high energy and another of much lower energy. Several investigators $(3,5,9$, 10) have shown experimentally that carbons activated at low temperatures $\left(<500^{\circ} \mathrm{C}\right)$ are "acidic" carbons; those activated at higher temperatures are "basic" carbons. "Acidic" carbons $(5,9,10)$ are defined as carbons which are capable of lowering the $\mathrm{pH}$ of neutral or alkaline distilled water, have a negative zeta (electrophoretic) potential, and are hydrophilic. "Basic" carbons are not really basic in the acid-base sense, as they interact with acidic solutions in a specific anion adsorption manner (3), but they are characterized by the ability to raise the $\mathrm{pH}$ of a neutral or acidic solution, a positive zeta potential, and hydrophobicity.

\section{EXPERIMENTAL}

Preparation of Carbons. Analytical reagent grade dextrose was charred in porcelain crucibles, with the covers left slightly ajar for exposure to air, in a muffle furnace at $600^{\circ} \mathrm{C}$ for 6 hours. The resultant char was ground to pass a 325 mesh $(44 \mu)$ screen. The -325 mesh material was then washed several times with triply distilled water, with the fines decanted during washing. The char was then dried at $200^{\circ} \mathrm{C}$ and stored in a vacuum desiccator until needed. Ten grams of char was placed in a $25 \mathrm{~mm}$ diameter, $20 \mathrm{~cm}$ long quartz tube, and retained by quartz wool plugs. The tube was mounted in a tube furnace and held at the desired temperature. Mixed gases of quantitative composition, obtained from Liquid Carbonic
Corp., Detroit, Michigan (concentrations accurate to $1 \%$ of stated values, according to supplier), were passed through the tube at a high flow rate $(>200 \mathrm{l} /$ hour) for 6 hours. The tube was then removed from the furnace and allowed to cool with a continuous flow of pure nitrogen flowing through $\left(<0.01 \% \mathrm{O}_{2}\right)$. After the tube had reached room temperature, the carbon was transferred to an evacuable Pyrex container with a high-vacuum stopcock affixed. The activated carbons were then kept under vacuum until withdrawn for analysis by IRS spectroscopy.

IRS Spectra. A Wilks Model 45DB IRS accessory (Wilks Seientific Corp., South Norwalk, Connecticut) was employed in the sample compartment of a Perkin-Elmer 621 infrared spectrophotometer. Because of the high refractive index of carbon, it is necessary to use an IRS crystal of either silicon or germanium. It was decided to use germanium crystals in this study, as they can be used, in a double-beam arrangement, to $15 \mu\left(667 \mathrm{~cm}^{-1}\right)$. The Model 45DB utilizes equal and identical sample and reference beam mirror systems (they are actually mirror images in geometry), thus equalizing atmospheric absorption and allowing compensation of the germanium lattice vibrations with an identical crystal in the reference beam.

Both germanium crystals employed were $0.5 \mathrm{~mm}$ thick, $5 \mathrm{~mm}$ wide, and $12.5 \mathrm{~mm}$ long, with $45^{\circ}$ face angles. (The Model 45 is designed for only that fixed angle.) This geometry provides 25 reflections (with beam divergence effects neglected) at the crystal surfaces. The powdered carbon samples were transferred from their evacuated storage containers and placed in physical contact with the IRS crystal. The Model 45 crystal holder acted to hold the powder in place. (To avoid breaking the thin $0.5-\mathrm{mm}$ crystals, it is advisable to use a piece of a wide rubber band between the powder and the sample holder plate to equalize the pressure, although this procedure is not absolutely necessary.)

A Perkin-Elmer 621 was used because of the inherent electronic stability and large signal-to-noise ratio of the instrument at $5 \times$ 
and $10 \times$ scale expansion, which was routinely needed to obtain these spectra.

The general problems and experimental parameters involved in internal reflection spectroscopy are discussed by Harrick (12) and Wilks (13-15). The application of IRS to the study of powders of high optical density (16) and activated carbon $(17,18)$ has also been discussed previously.

In general, it is not possible to guarantee identical and uniform physical contact of each and every powder sample to the IRS crystal; however, as the carbons employed in this study came from the same batch, it is assumed that only minor differences due to particle size and packing existed in the IRS sample arrangement.

\section{DISCUSSION OF RESULTS}

It had been previously noted $(17,18)$ that IRS spectra of commercial carbons showed very broad absorption bands in the 2000 $1000 \mathrm{~cm}^{-1}$ region. As difficulties were encountered with respect to characterizing the activation conditions of commercial carbons, the logical next step was then to prepare laboratory-activated carbons, utilizing a very pure starting material and uniform activating conditions, in order to attempt to obtain better defined IRS absorption bands.

Activated sugar char has been used extensively in the past when such reproducible and well-defined carbons were desired $(3,6$, $9,10)$. A uniform starting material was prepared by charring dextrose at $600^{\circ} \mathrm{C}$, and this material was then activated under controlled atmosphere and temperature condi- tions. Two different series of activation conditions are reported here: a series of sugar carbons activated in $1 \% \mathrm{O}_{2}-99 \% \mathrm{~N}_{2}$ for 6 hours at $300^{\circ}, 400^{\circ}, 500^{\circ}, 600^{\circ}$, and $700^{\circ} \mathrm{C}$, and a series of sugar carbons activated in $5 \%$ $\mathrm{O}_{2}-45 \% \mathrm{CO}_{2}-50 \% \mathrm{~N}_{2}$ for 6 hours at $300^{\circ}$ and $400^{\circ} \mathrm{C}$ and for 3 hours at $600^{\circ}$ and $700^{\circ} \mathrm{C}$.

The IRS spectra for the carbons within each series show the same general features from one sample to the next, but the relative intensities of the same functional group absorptions show some dependence on the temperature of activation. Tables I and II summarize the band positions and intensities for the two series of carbons.

Because of the dependence of IRS spectra on the particle size of the material being examined $(12,16)$, it is possible to make only relative intensity observations among the bands of a given spectrum. However, all the activated carbons reported on here were prepared from one batch of starting material, so the particle-size distributions should be close enough to permit observation of major trends.

In order to examine the spectra and assign the absorption bands to definite surface functional groups, it is necessary to examine some of the data of other investigators with respect to the structure of the carbon surface as well as its reactivity. Hennig (20, 21) showed that the reactivity of single crystals of graphite to molecular oxygen is predominantly at the prismatic faces (edges of the layer planes). This was done both by microscopic observation of etching and by an elegant experiment in which Hennig cleaved a

TABLE I

Band Positions and Retative In'tensities ${ }^{a}$ for Sugar Carbons Activated in $1 \% \mathrm{O}_{2}-99 \% \mathrm{~N}_{2}$

\begin{tabular}{|c|c|c|c|c|c|}
\hline \multirow{2}{*}{ Band $\left(\mathrm{cm}^{-1}\right)$} & \multicolumn{5}{|c|}{ Temperature of activation $\left({ }^{\circ} \mathrm{C}\right)$} \\
\hline & 300 & 400 & 500 & 600 & 700 \\
\hline $1750-1770$ & $(1765) \mathrm{m}$ & $(1750) \mathrm{s}$ & $(1770) \mathrm{m}$ & $(1770) \mathrm{m}$ & $(1750) \mathrm{m}$ \\
\hline $1710-1750$ & $(1740) \mathrm{m}$ & $(1710) \mathrm{s}$ & $(1750) \mathrm{m}$ & $(1720) \mathrm{m}$ & $(1710) \mathrm{m}$ \\
\hline $1620-1690$ & $(1640) \mathrm{vw}$ & $(1680) \mathrm{vw}$ & $(1650) \mathrm{W}$ & $(1620) \mathrm{vw}$ & - \\
\hline & & & $(1690) \mathrm{w}$ & $(1660) \mathrm{w}$ & \\
\hline $1590-1625$ & $(1590) \mathrm{m}$ & $(1625) \mathrm{s}$ & $(1595) \mathrm{s}$ & $(1590) \mathrm{w}$ & $(1590) \mathrm{w}$ \\
\hline $1510-1560$ & - & $(1520)$ vw & $(1550) \mathrm{s}$ & $(1560) \mathrm{s}$ & $(1520) \mathrm{m}$ \\
\hline $1140-1230$ & $(1150) ?$ & $(1180-1230) \mathrm{s}$ & $(1140) ?$ & $(1150)$ vs & $(1140-1180) \mathrm{s}$ \\
\hline
\end{tabular}

${ }^{a}$ v-very; w-weak; m-medium; s-strong. 
TABLE II

Band Positions and Relative Intensities for Sugar Carbons Activated in 5\% $\mathrm{O}_{2}$ $45 \% \mathrm{CO}_{2}-50 \% \mathrm{~N}_{2}$

\begin{tabular}{|c|c|c|c|c|}
\hline \multirow{2}{*}{ Band $\left(\mathrm{cm}^{-1}\right)$} & \multicolumn{4}{|c|}{ Temperature of activation $\left({ }^{\circ} \mathrm{C}\right)$} \\
\hline & 300 & 400 & 600 & 700 \\
\hline $1750-1770$ & $(1770) \mathrm{m}$ & $(1750) \mathrm{s}$ & $(1750) \mathrm{w}$ & $(1770) \mathrm{w}$ \\
\hline $1710-1750$ & $(1720)$ s & $(1710) \mathrm{m}$ & $(1700) \mathrm{s}$ & $(1710) \mathrm{m}$ \\
\hline $1620-1690$ & $(1650) \mathrm{vw}$ & $(1670) \mathrm{vw}$ & - & $(1660) \mathrm{W}$ \\
\hline $1590-1625$ & $(1600) \mathrm{m}$ & $(1605) \mathrm{s}$ & $(1600) \mathrm{m}$ & $(1590) \mathrm{m}$ \\
\hline $1510-1560$ & $(1555) \mathrm{s}$ & $(1520) \mathrm{m}$ & $(1565) \mathrm{m}$ & $(1450) \mathrm{m}$ \\
\hline $1140-1230$ & $(1210) \mathrm{s}$ & $(1180-1240) \mathrm{s}$ & $(1200) \mathrm{m}$ & $(1140-1220) \mathrm{s}$ \\
\hline
\end{tabular}

single crystal of graphite five times, thus increasing the basal plane surface area by a factor of six while leaving the prismatic surface area constant. The same amount of oxygen could be chemisorbed (and desorbed at $1000^{\circ} \mathrm{C}$ as $\mathrm{CO}$ and $\mathrm{CO}_{2}$ ) both before and after the cleaving (21), indicating that the predominant activity of graphite to oxygen is at the basal plane edges. The implication of this is that the types of surface oxides to be expected should closely parallel those encountered in normal organic oxidation chemistry.

In Figs. 1 and 2, there are a pair of bands observed at $1710-1750$ and $1750-1770 \mathrm{~cm}^{-1}$ in each spectrum, from the $300^{\circ}$ to the $700^{\circ} \mathrm{C}$ activated carbon. Figure 2 shows that the

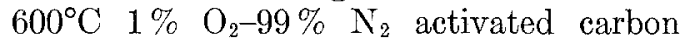
shows a merging of these two bands, and note that the merging is very extensive in the $500^{\circ}$ and $700^{\circ} \mathrm{C}$ carbons. In a previous paper (18), a broad absorption band in this same region was noted for both commercial activated carbon and "ultrapure" graphite, but not for carbon black. In this study (18), it was suggested that the absorption band belonged to a carboxylic acid anhydride. In the spectra of Figs. 1 and 2, this pair of bands corresponds well with those to be expected for a pair of adjacent carboxylic acids. Because of the ring structure of the carbon basal planes, it is reasonable to expect that aromatic acids, similar to the phthalic acids, would be created upon oxidation of the edges of the ring structure. It is possible that such adjacent carboxyl groups are then responsible for the broad band previously (18) ascribed to an anhydride.

Previous acid-base neutralization studies by Boehm et al. $(6,22)$ suggested the presence of a pair of carboxylic acids on low temperature oxidized carbons. These investigators employed both $\mathrm{HCO}_{3}^{-}$and $\mathrm{CO}_{3}^{-}$as titrants for acidic carbon surface oxides, and found that when the carbons were completely oxidized in oxygen, the ratio of the amounts of oxides neutralized by the two weak bases approached 1:1. As the $\mathrm{pK}_{a}$ 's of the conjugate acids $\mathrm{H}_{2} \mathrm{CO}_{3}$ and $\mathrm{HCO}_{3}^{-}$are 6.4 and 10.3, respectively, and in order to observe an end point in such a titration, the acid being titrated should be at least two orders of magnitude stronger than the conjugate acid of the base employed (23), the $\mathrm{pK}_{a}$ 's of the surface acids titrated by Boehm et al. $(6,22)$ must be in the ranges (a) $\mathrm{pK}_{a}<4.4$ and (b) $4.4<\mathrm{pK}_{a}<8.3$. The two carboxylic acid groups of several dicarboxylic acids have dissociation constants which fit these ranges. Several examples of these are given in Table III. It can be seen that separation in $\mathrm{pK}_{a}$ 's of 1 to 3 is typical for dicarboxylic acids. In the case of the isomers of phthalic acid, however, only the ortho isomer really fits the ranges observed from Boehm's experiments.

Puri (25) showed that the amount of $\mathrm{CO}_{2}$ evolved from an activated sugar carbon upon degassing at $1200^{\circ} \mathrm{C}$ was equal, on an equivalence basis, to the amount of $\mathrm{NaOH}$ neutralized by the carbon. He obtained similar results with activated coconut shell char, and with Spheron 6, Mogul, and Mogul A (carbon blacks) (25).

With respect to adjacent carboxyl groups, Puri (25) showed conclusively that 1 mole of $\mathrm{Br}_{2}$ was fixed by the carbon surface after the elimination of 2 moles of $\mathrm{CO}_{2}$ by partial or 


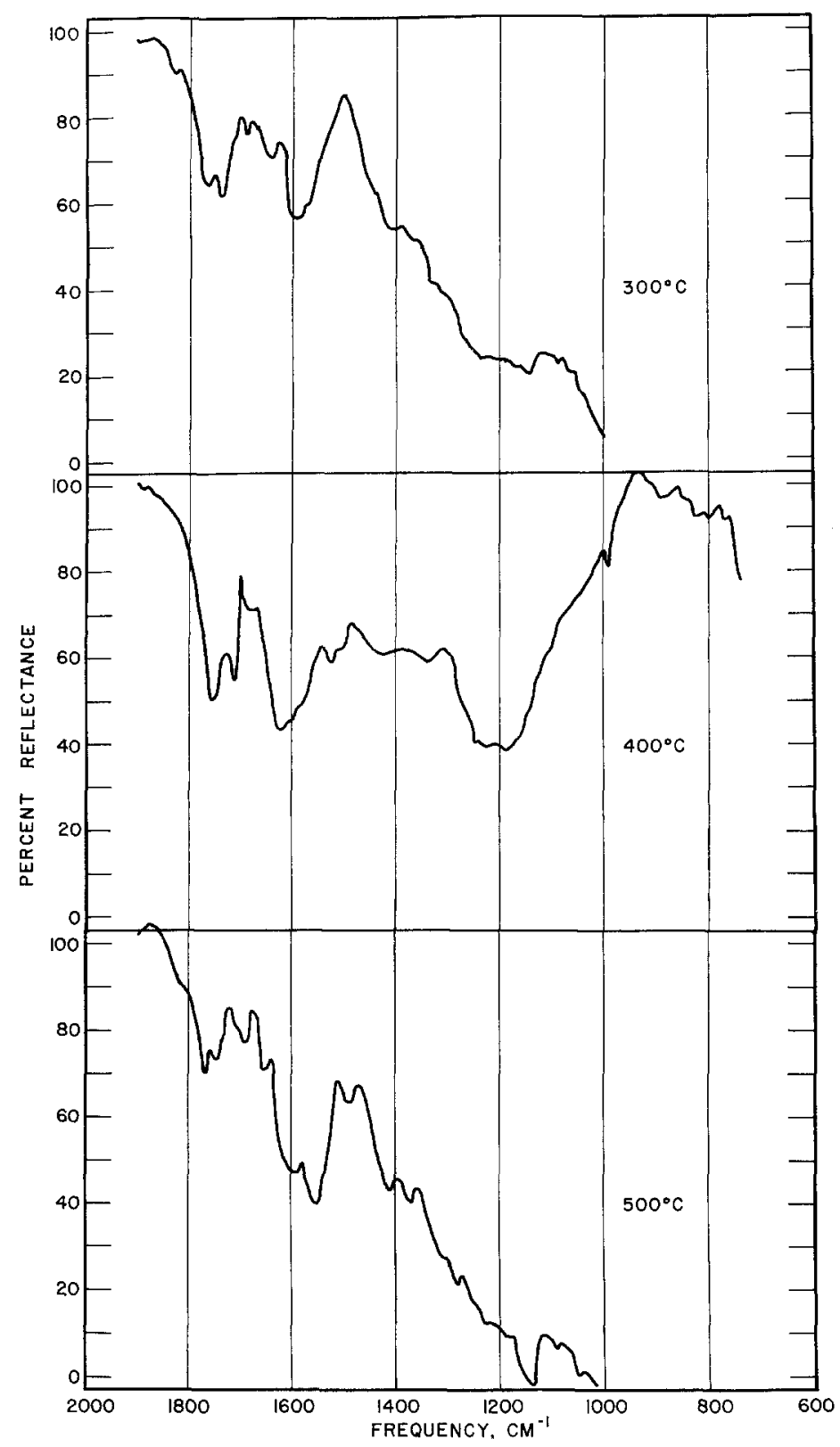

FIg. 1. IRS spectra (10X, DB germanium baseline subtracted) of sugar carbons activated in $1 \% \mathrm{O}_{2}-$ $99 \% \mathrm{~N}_{2}$ for 6 hours at $300^{\circ}, 400^{\circ}$, and $500^{\circ} \mathrm{C}$. The carbon contents of the $400^{\circ} \mathrm{C}$ and $500^{\circ} \mathrm{C}$ samples are $72.8 \%$ carbon and $74.2 \% \mathrm{C}$ (Spang Microanalytical Laboratory, Ann Arbor, samples dried 24 hours at $200^{\circ} \mathrm{C}$ prior to analysis).

complete outgassing. The added bromine was stable even to outgassing at $1200^{\circ} \mathrm{C}$. This, combined with the neutralization and infrared IRS data, confirms the existence of adjacent carboxyl groups at the edges of the basal planes, which come off as $\mathrm{CO}_{2}$ and leave a double bond between the remaining carbon atoms. It should also be pointed out that an appreciable amount of bromine was fixed even before $\mathrm{CO}_{2}$ was removed by Puri (25), indicating some degree of unsaturation to be present beforehand. 


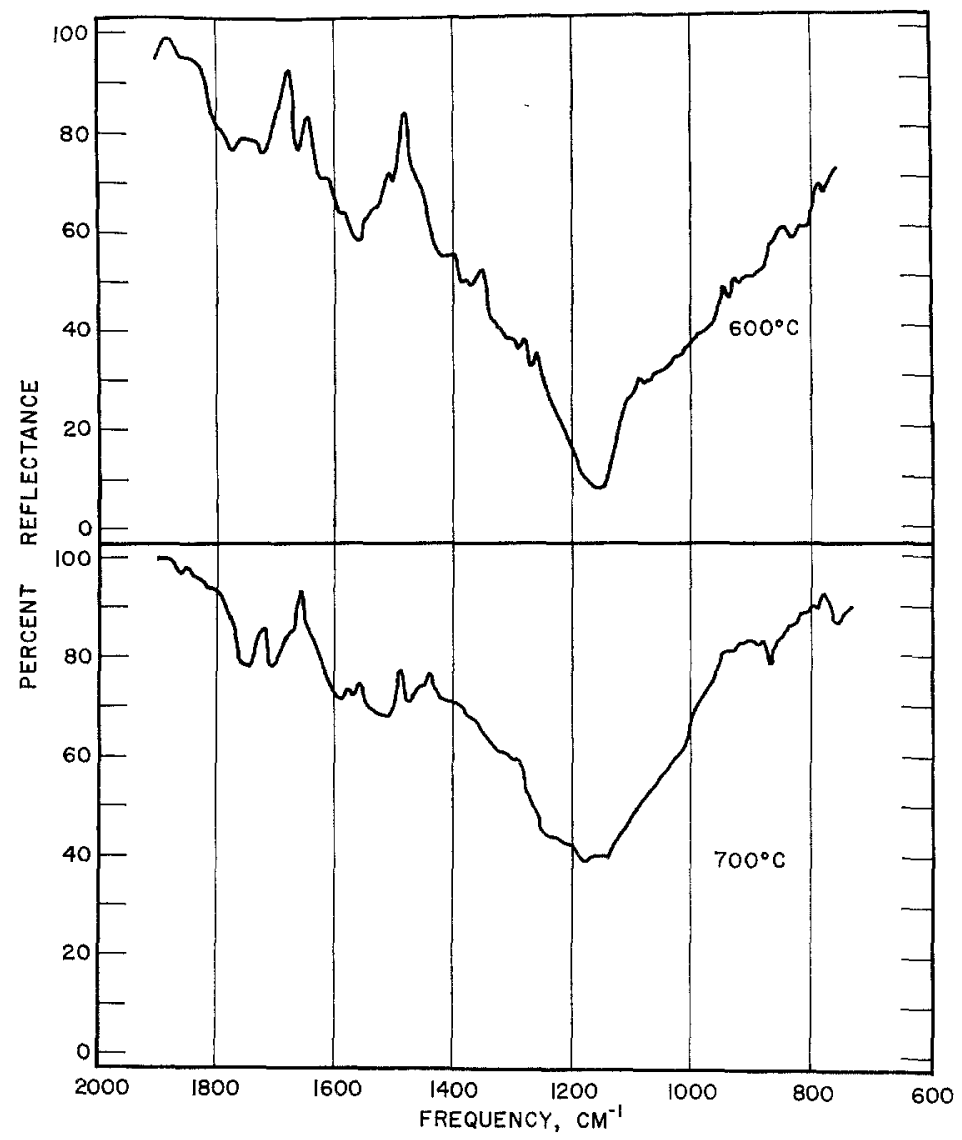

FIG. 2. IRS spectra ( $10 \mathrm{X}$, baseline subtracted) of sugar carbons activated in $1 \% \mathrm{O}_{2}-99 \% \mathrm{~N}_{2}$ for 6 hours at $600^{\circ}$ and $700^{\circ} \mathrm{C}$. Carbon contents of $600^{\circ} \mathrm{C}$ and $700^{\circ} \mathrm{C}$ samples are $82.8 \%$ carbon and $91.6 \%$, respectively.

TABLE III

Dissociatron Constants of Dicarboxylic ACIDS IN WATER (24)

\begin{tabular}{lcc}
\hline \multicolumn{1}{c}{ Acid } & $\mathrm{pK}_{1}$ & $\mathrm{pK}_{2}$ \\
\hline o-Phthalic & 2.89 & 5.51 \\
$m$-Phthalic & 3.54 & 4.60 \\
-Phthalic & 3.51 & 4.82 \\
Cyclohexane-1, 1-dicarboxylic & 3.45 & 6.11 \\
Malic & 3.40 & 5.11 \\
Succinic & 4.16 & 5.61 \\
Oxalic & 1.23 & 4.19 \\
Malonic & 2.83 & 5.69 \\
\hline
\end{tabular}

Carboxylic acids are noted for their ability to readily decarboxylate at rather moderate temperatures (26). The data of Puri (25) indicate that all the $\mathrm{CO}_{2}$ is removed from the carbon surface above $600^{\circ} \mathrm{C}$. Zarif'yanz et al.
(4) showed that $\mathrm{CO}_{2}$ begins to "desorb" from graphite below $200^{\circ} \mathrm{C}$ and is completely removed at $600^{\circ} \mathrm{C}$, whereas $\mathrm{CO}$ comes off between $300^{\circ}$ and $800^{\circ} \mathrm{C}$. Boehm (6) noted that evolution of gas is noted upon heating activated sugar char to $200^{\circ} \mathrm{C}$; this is probably $\mathrm{CO}_{2}$.

The other major spectral feature in the carbonyl region of the $1 \% \mathrm{O}_{2}-99 \% \mathrm{~N}_{2}$ activated carbons in Figs. 1 and 2 is the pair of absorption bands at 1590-1625 and 1510$1560 \mathrm{~cm}^{-1}$, respectively. In earlier publications utilizing IRS for the examination of carbon surfaces, intense bands were observed in each case near $1600 \mathrm{~cm}^{-1}$ and $1500 \mathrm{~cm}^{-1}$ for active carbon, but not on graphite or carbon black (some absorption was observed around $1500 \mathrm{~cm}^{-1}$ on graphite) (17, 18). Garten and coworkers, however, em- 
ploying a transmission IR technique, noted an intense band around $1600 \mathrm{~cm}^{-1}$ in the spectrum (27) of Carbolac 1, a carbon black. Similar bands have been observed by Friedel and Queiser (28) and Brown (29) in coals and cellulose chars. The spectra of these materials also show a strong band at $1600 \mathrm{~cm}^{-1}$. However, transmission spectra of materials of greater than $85 \%$ carbon do not exhibit any contrast, and it is unlikely that close parallels can be drawn between the spectra of incompletely oxidized carbonaceous materials $(27-29)$ and activated carbon.

Because of the association of the adsorption of phenols on active carbon with the presence of carbonyl oxygen suggested earlier (19), the carbons activated in $1 \%$ $\mathrm{O}_{2}-99 \% \mathrm{~N}_{2}$ were examined for their $p$-nitrophenol adsorption behavior. Figure 3 illustrates the experimental data for the adsorption isotherms, obtained as described earlier (19), and Fig. 4 relates the $p$-nitrophenol adsorption capacities for an equilibrium solution concentration of $800 \mu \mathrm{M}$ to the temperature of activation. From Figs. 3 and 4 , it appears that the surface group responsible for this adsorption mechanism goes through a surface concentration maximum at about $500^{\circ} \mathrm{C}$ activation temperature. From the mechanistic study of the previous paper (19), where a donor-acceptor complex formation was proposed involving carbonyllike oxygen and the aromatic ring of the

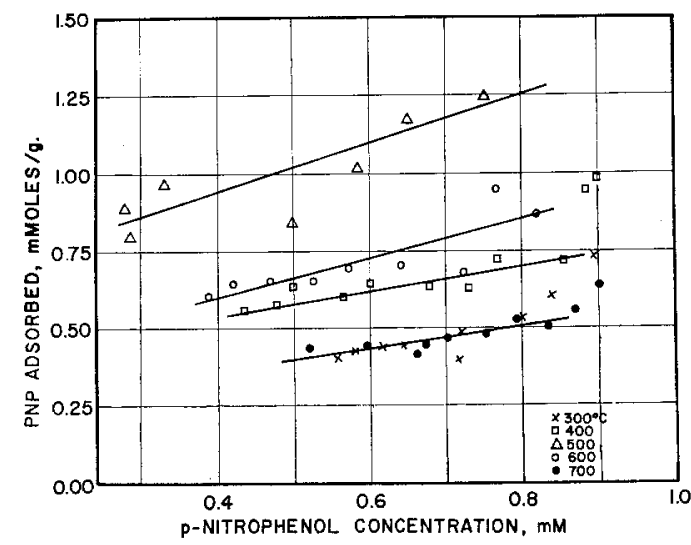

FIG. 3. $p$-Nitrophenol adsorption isotherms for sugar carbons activated at $300^{\circ}-700^{\circ} \mathrm{C}$ in $1 \%$ $\mathrm{O}_{2}-99 \% \mathrm{~N}_{2}$ as a function of activation temperature. Procedure given in reference 19.

Journal of Colloid and Interjace Science, Vol. 33, No. 2, June 1970

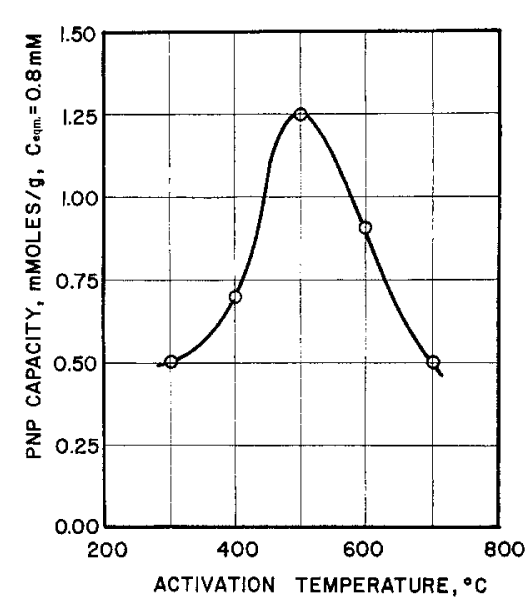

Frg. 4. p-Nitrophenol capacities for sugar carbons activated in $1 \% \mathrm{O}_{2}-99 \% \mathrm{~N}_{2}$ as a function of activation temperature. The surface areas of these carbons increased regularly from $158 \mathrm{~m}^{2} / \mathrm{g}$ for the $300^{\circ}$ carbon to $318 \mathrm{~m}^{2} / \mathrm{g}$ for the $700^{\circ}$ carbon.

phenol, it would seem that the spectra of Figs. 1 and 2 should reflect the trend observed in Fig. 4 with respect to activation temperature. Careful examination of Figs. 1 and 2, along with the intensities and band maxima given in Table $I$, reveals only one sequence which matches the adsorption sequence. At $300^{\circ} \mathrm{C}$ activation temperature, the band on the high-energy side $\left(1590 \mathrm{~cm}^{-1}\right.$ in this case) of the $1600 \mathrm{~cm}^{-1}$ pair is the only observed band, and it is of medium intensity. In the $400^{\circ} \mathrm{C}$ carbon, this band (now at $1625 \mathrm{~cm}^{-1}$ ) is strong, and a very weak band shows up at $1520 \mathrm{~cm}^{-1}$. In the $500^{\circ} \mathrm{C}$ carbon, the low-energy band $(1550$ $\mathrm{cm}^{-1}$ ) is stronger than the high-energy one $\left(1595 \mathrm{~cm}^{-1}\right)$. In the $600^{\circ} \mathrm{C}$ carbon, the lowenergy band $\left(1560 \mathrm{~cm}^{-1}\right)$ predominates, and in the $700^{\circ} \mathrm{C}$ carbon, both bands are beginning to disappear, although the lowenergy band clearly is the more intense.

An aromatic ketone would be expected to appear at $1680-1700 \mathrm{~cm}^{-1}$, and this is clearly not observed. The presence of such a $\mathrm{C}=\mathrm{O}$ group at the edge of a regular aromatic structure would force the ring system into the cyclohexadiene structure of a quinone, however. An isolated quinone would absorb at about $1660-1690 \mathrm{~cm}^{-1}$. Quinones have been identified polarographically by two studies, one on carbon black (31), which involved the finding of an anodic wave corresponding to quinones, which could be elimi- 
nated by reduction with $\mathrm{LiAlH}_{4}$, and the more recent one (32), which found the same result for active carbon. The presence of an enol, however, which would involve conjugated 1,3-dicarbonyl structures, would explain the observed spectrum, as the enolic form of such a compound absorbs in the 1640-1540 $\mathrm{cm}^{-1}$ region (33). Brown (29) suggested this as an assignment for the 1600 $\mathrm{cm}^{-1}$ band, and Garten et al. (27) also accepted this assignment.

The strange changes in the spectrum in the $1510-1625 \mathrm{~cm}^{-1}$ region certainly need to be examined more carefully with respect to the adsorption phenomena associated with $\mathrm{C}=\mathrm{O}$ groups. It is quite possible that there is strong interaction all along the edges of the basal planes between carboxyl and carbonyl groups. Certainly the decarboxylation which takes place at these temperatures should result in the type of conjugation required to form enolic groups. These double bonds may also show up in the IRS spectra.

Figure 5 shows the IRS spectra of a series of carbons activated in $5 \% \quad \mathrm{O}_{2}-45 \% \quad \mathrm{CO}_{2}-$ $50 \% \mathrm{~N}_{2}$. These generally had lower capacities for $p$-nitrophenol (0.6 to $0.8 \mathrm{mM}$ / $\mathrm{gm})$, indicating perhaps that the $\mathrm{CO}_{2}$ had quite an effect of suppression of either the formation of surface oxides or surface area at these temperatures. The $\mathrm{O}_{2}-\mathrm{CO}_{2}-\mathrm{N}_{2}$ carbons do not show the same well-defined pair of carboxylic acids seen in Figs. 1 and 2, although the absorption band is certainly present throughout (see Table II). The same general structure is observed in the 1600

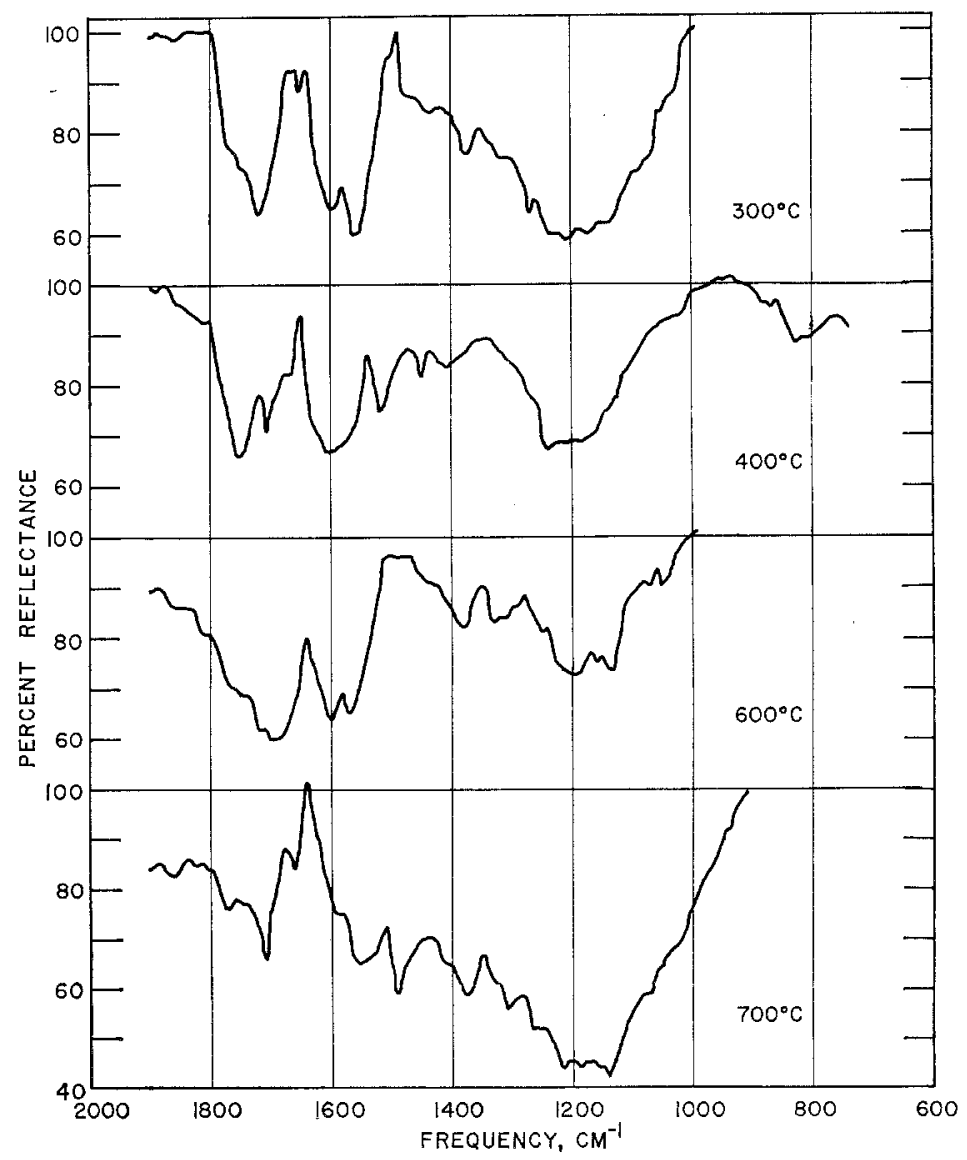

FIG. 5. IRS spectra of sugar carbons activated in $5 \% \quad \mathrm{O}_{2}-45 \% \quad \mathrm{CO}_{2}-50 \% \mathrm{~N}_{2}$ at $300^{\circ}$ and $400^{\circ} \mathrm{C}$ for 6 hours, and $600^{\circ}$ and $700^{\circ} \mathrm{C}$ for 3 hours. Carbon contents for $300^{\circ}, 400^{\circ}, 600^{\circ}$, and $700^{\circ} \mathrm{C}$ samples are $79.0 \%$, $75.6 \%, 89.2 \%$, and $87.5 \%$ carbon, respectively. (Samples activated in pure $\mathrm{CO}_{2}$ for 6 hours at $300^{\circ} \mathrm{C}$ and $700^{\circ} \mathrm{C}$ had carbon contents of $82.4 \%$ and $91.5 \%$, respectively.) 
$\mathrm{cm}^{-1}$ region. A band at $1380 \mathrm{~cm}^{-1}$, observed weakly in the $500^{\circ}$ and $600^{\circ} \mathrm{C}$ portions of Fig. 2 and not mentioned in Tables I and II, is observed in three of the four spectra of Fig. 5. This small band is difficult to assign, however.

The most predominant feature in all the spectra is the broad band observed in the 1140 to $1230 \mathrm{~cm}^{-1}$ region. This band is not temperature dependent, over the range $300^{\circ}$ to $700^{\circ} \mathrm{C}$. It is in the singly bonded oxygen region, and thus could correspond to a wide variety of functional groups. It may fit with an -OH bending assignment, but there were no bands observed in the -OH stretching region $\left(3750-3000 \mathrm{~cm}^{-1}\right)$. The $\mathrm{OH}$ stretching vibration band is normally more intense than the $\mathrm{OH}$ bending vibration, and even though IRS will enhance the longer wavelength band (12-15) (in this case by $8 \mu / 3 \mu=2.7$ ), this enhancement cannot account for the lack of an $\mathrm{OH}$ stretching band.

\section{SUMMARY}

There is little doubt but that internal reflectance spectroscopy has provided a muchimproved technique for the study of optically opaque solids, without the scattering and absorption problems which are inherent in transmission spectroscopy. Its application to the examination of the surface of active carbon reported here has settled some questions and posed some additional ones. The presence of significant amounts of carbonyl and carboxyl groups can now be directly substantiated, even though it has long been speculated. The behavior of active carbon as an adsorbent has to be related to the surface functionality of this material; certainly the evidence for chemical interaction at the surface between carbonyl and carboxyl groups and organic adsorbates is mounting (19). Enhancement of the adsorption capacity of active carbon may well be accomplished by increasing the concentration of the appropriate surface functional groups. The present work should serve as a beginning for a detailed study of the chemistry of the activation process itself.

\section{ACKNOWLEDGMENTS}

The authors would like to express their appreciation to the Chemistry Department of the
University of Toledo for the use of their PerkinElmer 621, and to Paul A. Wilks, Jr., of Wilks Scientific and N. J. Harrick of Harrick Scientific for their advice and helpful suggestions.

This research was supported by the Federal Water Pollution Control Administration, through grants $16020 \mathrm{ELH}$ and WP00706.

\section{REFERENCES}

1. Smith, A., Proc. Roy. Soc. Ser. $A$ 12, 424 (1863).

2. Langmuir, I., J. Amer. Chem. Soc. 37, 1139 (1915).

3. Frumkin, A., Kolloid Z. 51, 123 (1930).

4. Zarif'yanz, Y. A., Kiselev, V. F., Lezhnev, N. N., Nikitina, O. V., Carbon 5, 127 (1967).

5. KRUY', H. R., AND DEKadT, G. S., Kolloid $Z$. 47, 44 (1928).

6. Boенm, H. P., Advan. Catal. 16, 179 (1964).

7. Donnet, J. B., Carbon 6, 161 (1968).

8. Shelef, M., and Walker, P. L., JR., Carbon 5, 93 (1967).

9. Garten, V. A., and Weiss, D. E., Rev. Pure Appl. Chem., 7, 69 (1957).

10. Stemnere, B., "Adsorption and Exchange of Ions on Activated Charcoal." Almquist and Wiksells, Uppsala, Sweden, 1944.

11. Rrvin, D., "Proc. Conf. Carbon 5th, 1961," Pergamon Press, N.Y., vol. 2, 203 (1963).

12. HaRkick, N. J., "Internal Reflection Spectroscopy." Interscience Publishers, New York, 1967.

13. Wrцks, P. A., JR., Appl. Spectrosc. 22, 782 (1968).

14. WILKs, P. A., JR., Appl. Spectrosc. 23, (1969).

15. Wilks Seientific Corp., S. Norwalk, Conn., "Internal Reflection Spectroscopy," Vol. 1, 1965.

16. MatTson, J. S., MARK, H. B., JR., AND WEBER, W. J., JR., Proc. 20th Mid-America Symposium on Spectroscopy, Chicago, May, 1969, Plenum Press (in press).

17. Matison, J. S., MaRK, H. B., JR., and Weber, W. J., JR., Anal. Chem. 41, 355 (1969).

18. Matison, J. S., And Mark, H. B., JR., $J$. Colloid and Inierface Sci., 31, 131 (1969).

19. Matison, J. S., Mark, H. B., JR., Malbin, M. D., Weber, W. J., JR., and CritTtenden, J. C., J. Colloid and Interface Sci. 31, 116 (1969).

20. Hennig, G. R., J. Chim. Phys. 58, 12 (1961).

21. Hennig, G. R., "Proc. Conf. Carbon 5th, 1961," Pergamon Press, N.Y. vol. 1, 143 (1962).

22. Boенм, H. P., Diehl, E., Heck, W., ANo SaPpoK, R., Angew Chem. Intern. $E d$. Engl. 3, 669 (1964). 
23. Moss, M. L., Elliot, J. H., and Hali, R. T., Anal. Chem. 20, 784 (1948).

24. "Handbook of Chemistry and Physics," 44th ed., p. 1753. Chemical Rubber Publishing Co., Cleveland, Ohio, 1963.

25. Puri, B. R., Carbon 4, 391 (1966).

26. Roberts, J. D., and Caserio, M. C., "Basic Principles of Organic Chemistry," pp 468, 1002. W. A. Benjamin, Inc., New York, 1964.

27. Garten, V. A., Weiss, D. E., And Wilisis, J. B., Aust. J. Chem. 10, 295 (1967).
28. Friedel, R. A., ANd Queiser, J. A., Anal. Chem. 28, 22 (1956).

29. Brown, J. K., J. Chem. Soc. 1955, 744.

30. Friedel, R. A., "Proc. Conf. Carbon 4th, 1959," Pergamon Press, N.Y., p. 321 (1960).

31. Hallum, J. V., AND Drushel, H. V., J. Phys. Chem. 62, 110 (1958).

32. Jones, J. F., AND KAYE, R. C., J. Electroanal. Chem. 20, 213 (1969).

33. Dyer, J. R., "Applications of Absorption Spectroscopy of Organic Compounds." Prentice-Hall, Englewood Cliffs, New Jersey, 1965. 